DOI: $10.14451 / 1.198 .148$

\title{
COVID-19. ИТОГИ ДЕЯТЕЛЬНОСТИ СИСТЕМЫ ЗДРАВООХРАНЕНИЯ
}

\author{
(C) 2021 Сибилёв Дмитрий Владимирович \\ аспирант ИГСУ РАНХиГС \\ Институт государственной службы и управления Российской академии народного хозяйства \\ и государственной службы при Президенте РФ (РАНХиГС), Россия, Москва \\ Email: sdmitry2002@gmail.com \\ (c) 2021 Панова Татьяна Владимировна \\ кандидат экономических наук, \\ декан факультета Международного регионоведения и регионального управления \\ Институт государственной службы и управления Российской академии народного хозяйства \\ и государственной службы при Президенте РФ (РАНХиГС), Россия, Москва \\ Email: tv.panova@igsu.ru
}

В статье подводятся итоги работы системы здравоохранения в борьбе с новой коронавирусной инфекцией. Отмечены сильные и слабые стороны в системе здравоохранения, а также существующие проблемы на конец 2020 года.

Ключевые слова: пандемия, коронавирусная инфекция, заболеваемость, летальность, нехватка кадров, койко-места, защита.

Отрицательное влияние пандемии почувствовали на себе многие страны. 2 февраля 2020 года заболевание вносится в перечень особо опасных инфекций. Россия достаточно оперативно отреагировала на распространяющуюся инфекцию закрытием границ и активизацией санитарно-эпидемиологической службы путем информирования населения о смертельно опасном вирусе и методах защиты от него.

В 2020 году мировая экономика сократилась на $4,3 \%$, а глобальный долг увеличился до 281 триллиона долларов, что в 3,5 раза больше размера самой мировой экономики. По оценкам экспертов к концу 2021 года объем займов может дорасти до 300 триллионов*.

Президент РФ Владимир Путин в ходе первого в истории виртуального саммита «Большой двадцатки» сравнил масштаб проблем от пандемии с финансовым кризисом 2008-2009 годов, отметив, что пандемия грозит куда более серьезными последствиями **.

Сильнее всего пострадали экономически развитые страны, так как строгие карантинные меры в этих странах были введены с самого начала пандемии. Последствия негативного влияния пандемии почувствовали на себе

практически все российские компании в связи с ограничительным мерами и снижением потребительского спроса многих видов услуг и товаров. Наибольшему влиянию подверглись ретейлеры и производители промышленных товаров, товаров народного потребления, предприятия сферы услуг. В выигрыше оказались компании, сумевшие перестроиться на производство средств индивидуальной защиты, а также обеспечение населения повышенным спросом продуктов питания $* * *$.

Первые случаи заболевания COVID-19 официально были зарегистрированы в России 31 января 2020 года, один в Чите, второй в Тюмени. Заболевшие были гражданами Китая. Затем больные начали регистрироваться с марта 2020 г., количество которых стремительно нарастало (рис. 1).

В структуре общей смертности отмечается значительный прирост в 2020 г. в сравнении с предыдущим годом. При анализе умерших за период 2015-2019 г.г. в Российской Федерации наблюдалась стабильная динамика по снижению смертности с 1911,4 тысяч человек в 2015 году, до 1800,7 тысяч человек в 2019 г. Однако, количество умерших в 2020 г. составляет уже

\footnotetext{
*URL: https://lenta.ru/news/2021/03/25/posledstviya/ (дата обращения 06.04.2021)

** URL: https://iz.ru/1142620/2021-03-26/v-mid-rf-otcenili-poteri-mirovoi-ekonomiki-iz-za-pandemii-covid-19 (дата обращения 06.04.2021)

*** URL: https://www.kommersant.ru/ doc/4320006 (дата обращения 03.04.2021);
} 
2124479 человек, что на 323802 человека больше (табл. 1). В тоже время, согласно статистическим данным, количество умерших по причине коронавирусной инфекции составляет 104826 человек. Явных причин, связанных с таким резким возрастанием смертности в 2020 г., нет. Таким образом в 2020 году мы можем наблюдать достаточно высокий уровень «избыточная смертности».

Таким образом, по причине COVID-19 и осложнений, возникших на фоне данной инфекции, зарегистрировано за анализируемый период 118355 погибших.

В 2020 г. смертность в России выросла на $18 \%$. В конце марта начали умирать первые заразившиеся больные. В апреле количество погибших составило 1748 человек. В мае количество зарегистрированных погибших составило 7603 человека*.

Как и прогнозировалось в начале пандемии, пик заболеваемости и смертности приходится на декабрь 2020 г. В августе-сентябре отмечается умеренное снижение количества заболевших и умерших по причине коронавирусной инфекции.

По мере распространения смертельно опасного вируса на территории страны, российское здравоохранение столкнулось с серьезными проблемами. Основной проблемой стало слабое оснащение средствами индивидуальной защиты и необходимыми койко-местами регионов страны, отсутствие необходимой аппаратуры для обеспечения больных кислородом и ИВЛ. Однако благодаря оперативно принятым мерам многие проблемы, связанные с пандемией, удалось предотвратить. Наряду с этим, пришлось до минимума снизить объемы оказания плановой медицинской помощи, профилактические программы, диспансеризацию.

Начался массовый закуп лекарствен-

* Сборник Росстата «Здравоохранение России 2019»// Федеральная служба государственной статистики. URL: https:// gks.ru/ bgd/reg1/b19_34/Mainhtm (дата обращения 03.04.2021);

Таблица 1. Смертность в 2019 и 2020 гг. в РФ

\begin{tabular}{|l|l|}
\hline общее количество умерших за 2019 г. & 1800677 \\
\hline общее количество умерших за 2020 г. & 2124479 \\
\hline причина смерти COVID-19 & 104826 \\
\hline $\begin{array}{l}\text { COVID-19 не является основной причиной смерти, но оказал существенное } \\
\text { влияние на развитие смертельных осложнений заболевания }\end{array}$ & 13529 \\
\hline
\end{tabular}

Статистика смертности от COVID 19 в 2020 г. по месяцам

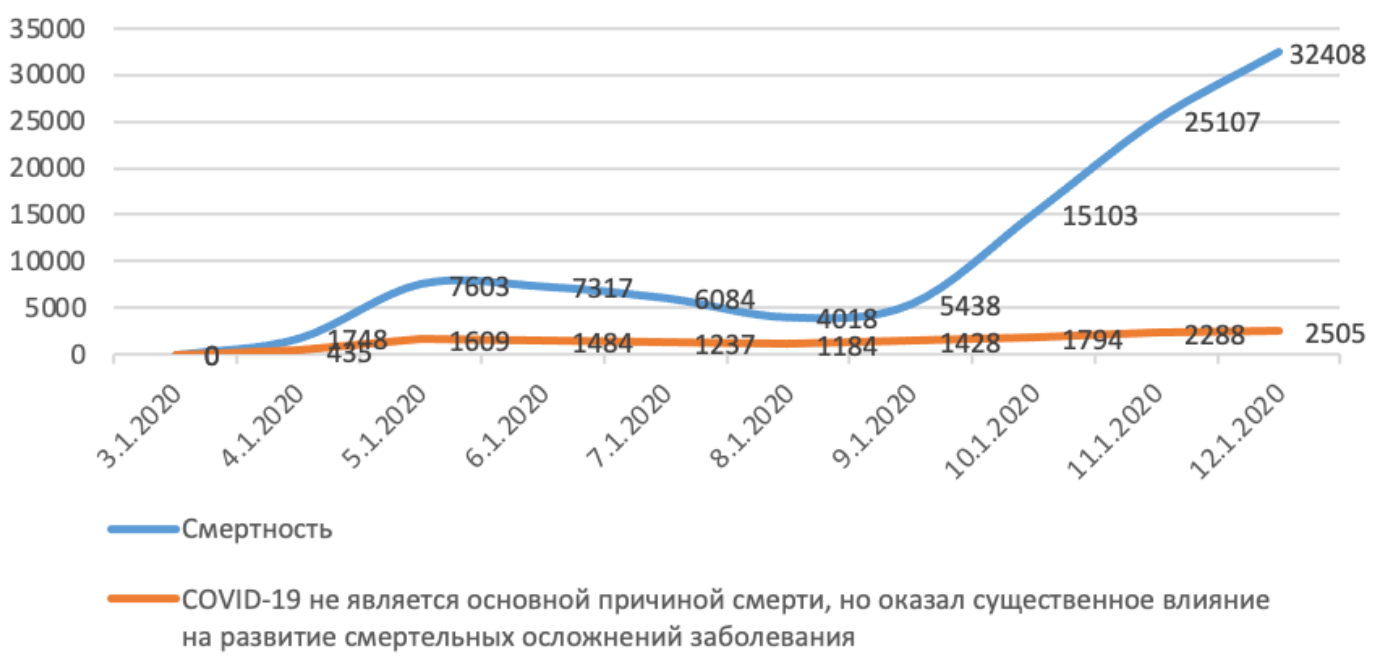

Рисунок 1. Статистика смертности от COVID 19 в 2020 г. по месяцам 
ных средств, рекомендованных для лечения COVID-19, что привело к выраженному дефициту отдельных лекарственных препаратов на фармацевтическом рынке. Такой повышенный спрос и востребованность лекарств заранее предвидеть было невозможно. К примеру, в 2020 г. гидроксихлорохина произвели в 173 раза больше, чем в 2019.

Для решения проблем, связанных с дефицитом лекарственных средств, был предпринят ряд мер. В частности, увеличился импорт лекарственных средств. Таким образом, в апреле 2020 г. импорт лекарственных средств оказался на 37\% выше аналогичного периода предшествовавшего года, активизировалось внутреннее производство лекарственных препаратов. Отрегулировались цены на лекарственные препараты, а также больные новой инфекцией получили возможность получать бесплатные препараты, что дало им возможность не зависеть от аптек.

В экстренном режиме было запущено строительство новых инфекционных больниц в связи с острой нехваткой койко-мест для нарастающего количества больных. В проблемах нехватки койко-мест существенную роль сыграла программа модернизации отрасли 2012-2018 гг. и закрытие «нерентабельных» стационаров, что привело к сокращению койко-мест на 15\%, а в некоторых регионах и более. Еще вначале пандемии было отмечена проблема нехватки койко-мест в стационарах. Однако данный вопрос был оперативно решен благодаря построенным новым инфекционным больницам.

Новые стационары построены по современным технологиям, их количество более 40 по всей России. На это было направлено более 100 млрд. рублей. На первых этапах распространения смертельного вируса было создано около 25 тысяч койко-мест с планированием увеличения до 95 тысяч мест. Однако этого оказалось абсолютно недостаточно и увеличение составило около 280 тысяч койко-мест, что в треть больше запланированного*.

Помимо постройки новых стационаров, было перепрофилировано под больных с COVID-19 более $20 \%$ действующих койко-мест. Перепрофилирование оказалось вполне быстрым решением проблемы острой нехватки мест в стационарах, так как многие больницы уже оказались оснащены необходимым оборудованием для ле- чения и диагностики. Однако перепрофилирование показало существенную нехватку остальных видов помощи населению.

Новые койко-места создавались в узкоспециализированных центрах, роддомах, противотуберкулезных центрах, хосписах, в связи с чем больные соответствующих категорий начали ощущать острый недостаток соответствующей помощи. Лечить пациентов становилось негде, больных направляли домой на амбулаторное долечивание и наблюдение. Все это привело к тому, что пациенты, не болеющие COVID-19, но имеющие другие хронические заболевания и состояния, требующие стационарного лечения, остались без соответствующей помощи и внимания. Многие плановые операции были перенесены на неопределенный срок, а больные направлены домой.

Ситуация с койко-местами в зависимости от региона страны разная. В 17 регионах страны все еще отмечается нехватка койко-мест, особенно в Санкт-Петербурге, Калининграде, Саратовской и Ростовской области. Здесь количество свободных коек на декабрь 2020 составляло менее 5\%.

Для увеличения количества койко-мест во многих регионах изменили принципы подхода к лечению. Больных старались преимущественно вести амбулаторно, госпитализируя только по тяжести состояния и по показаниям. В начале пандемии стационарно лечили всех больных COVID-19, даже с бессимптомным течением. Однако совсем скоро количество больных настолько увеличилось, что принципы госпитализации пришлось пересмотреть. Амбулаторно начали лечить даже больных с пневмонией, если она протекает в неосложненной форме. Основные жалобы больных были связаны с отказами в госпитализации и преждевременной выпиской из стационаров.

Вспышка пандемии показала, насколько остро стоит вопрос в стране с нехваткой профильных специалистов для лечения инфекционных заболеваний. С распространением пандемии вопрос нехватки специалистов инфекционного профиля только обострился. Стоит отметить, что в России все еще сохраняется отдельная специальность «Инфекционные болезни» и проводится лечение по данному профилю, чего давно нет во многих странах мира. Медицина России не была готова к такого рода массовой

\footnotetext{
* Число больничных коек на 100000 населения // Всемирная организация здравоохранения. URL: https://gateway. euro.who.int/ru/ (дата обращения 05.04.2021);
} 
инфекционной вспышке. В процессе модернизации медицины количество врачей сократилось на $12 \%$, чему способствовали колоссальные нагрузки, а также низкие заработные платы. Также уменьшению количества специалистов способствовало сокращение ставок в связи с перепрофилированием стационаров*. Важной проблемой было и то, что даже функционировавшие к тому времени отделения приходилось массово закрывать на карантин в связи с заболеванием медицинского персонала и больных.

Так, согласно имеющимся данным, в сельской местности врачей работает на декабрь 2020 г. на 36 тысяч меньше нужного, а средних медработников здесь меньше на 66 тысяч. По статистике, оклады врачей в 2019 г. составляли 12-35 тыс. р., медицинских сестер - 10-20 тыс. p. Остро возник вопрос стимулирования медицинских работников для работы в особо опасных условиях работы. Так, были организованы стимулирующие выплаты медицинским работникам, на осуществление которых направлена большая часть средств, выделенных для борьбы c COVID-19 (46,7 из 65 млрд. p.) [3]. На строительство новых стационаров и закуп необходимой аппаратуры - по 10 млрд. р.

Существенной проблемой в начале пандемии была острая нехватка средств индивидуальной защиты медицинских работников и населения, способствовавший повышенному спросу медицинских масок и перчаток, дезинфицирующих растворов. Система производства средств защиты была не готова к такому повышенному спросу. Повышенный спрос привел к росту цен на перечисленные средства. До начала распространения инфекции на территории страны действовало около 18 предприятий, выпускающих за сутки более 600 тысяч масок, обеспечивавшие спрос на них по всей стране. Развитие пандемии способствовало повышению спроса более, чем в 3 раза. Однако вопрос это был оперативно решен и цены урегулированы.

Этиотропного лечения коронавирусной инфекции пока нет, в связи с чем основная роль принадлежит профилактике заболевания и распространения данной инфекции. К концу 2020 г. большие надежды возлагаются на внедрение вакцины.

Россия первая страна в мире, приступившая к массовой вакцинации от коронавирусной инфекции. Для вакцинации взрослого населения разрешены три вакцины - Спутник, ЭпиВакКорона, Вакцина НИИ вакцин и сывороток ФМБА. В России отмечается нехватка финансирования научно-исследовательской отрасли. На научные исследования в России выделяется в 10 раз меньше средств, чем в развитых странах мира, в связи с чем изобретение новой вакцины большей частью заслуга предыдущих лет работы.

Несмотря на активную работу системы здравоохранения в связи с распространением опасной пандемии, к концу 2020 г. остается ряд нерешенных вопросов. Актуальной проблемой остается нехватка медицинского персонала, в связи с чем зачастую больные не могут дождаться приезда врача. Вызовы могут обрабатываться в течение нескольких суток, что вызывает самостоятельное обращение больных в лечебные учреждения, нарушая рекомендации не покидать дома и ждать приезда врача.

В 2020 г. на покупку автомобилей скорой медицинской помощи было выделено 5,2 млрд. рублей, однако дефицит машин скорой помощи все еще остался. По этой причине часто поступали жалобы на долгие ожидания скорой помощи. Существенным недостатком можно назвать отсутствие стимулирующих выплат вспомогательному персоналу, подвергающему себя риску наравне с медицинским персоналом. Отсутствие выплат стимулирующего характера привело к массовым увольнениям работников данной сферы, что создало нехватку кадров в данной области.

Таким образом, 2020 г. отметился пиком заболеваемости новой коронавирусной инфекцией и показал все сильные и слабые стороны системы здравоохранения страны. Российское здравоохранение скрывает действительные жертвы коронавирусной инфекции, иначе никак объяснить нельзя резко выросшие показатели смертности в 2020 г. Распространение пандемии показало, что функционирующая система не была готова к массовой вспышке инфекционной болезни, однако ряд мер, предпринятых своевременно, позволил избежать серьезных последствий и быстро решить возникшие проблемы. На финансирование вопросов, связанных с COVID-19, из федерального бюджета было вы-

\footnotetext{
* Стародубов В.И, Кадыров Ф.Н., Обухова О.В., Базарова И.Н., Ендовицкая Ю. В., Несветайло Н. Я. Влияние коронавируса COVID-19 на ситуацию в российском здравоохранении. Аналитический доклад. Версия 1.0. (по состоянию 26.12.2020 г.). 45 с.;
} 
делено достаточное количество денег, большая меры, катастрофических жертв COVID-19 избечасть из которых была направлена на стиму- жать не удалось, и вирус, как волна, прошелся по лирующие выплаты медицинским работникам. всей территории страны.

Тем не менее, несмотря на все предпринятые

\section{Библиографический список}

1. Стародубов В.И, Кадыров Ф.Н., Обухова О.В., БазароваИ.Н., Ендовицкая Ю.В., Несветайло Н.Я. Влияние коронавируса COVID-19 на ситуацию в российском здравоохранении. Аналитический доклад. Версия 1.0. (по состоянию 26.12.2020 г.). 45 с.;

2. Сборник Росстата «Здравоохранение России 2019»// Федеральная служба государственной статистики. URL: https://gks.ru/bgd/reg1/b19_34/Mainhtm (дата обращения 03.04.2021);

3. Moore K.A, Lipsit Ch.M., Barry J.M, Osterholm M. T. The future of the COVID-19 pandemic: Lessons learned from pandemic influenza COVID-19: The CIDRAP viewpoint. April 30, 2020. No. 9. URL: www.cidrap.umn.edu (дата обращения 04.04.2021);

4. Число больничных коек на 100000 населения // Всемирная организация здравоохранения. URL: https:/ gateway.euro.who.int/ru/ (дата обращения 05.04.2021);

5. URL: https://www.kommersant.ru/doc/4320006 (дата обращения 03.04.2021); 